\title{
Emotions in Education: Asian Insights on the Role of Emotions in Learning and Teaching
}

\author{
Ronnel B. King ${ }^{1} \cdot$ Junjun Chen ${ }^{2}$
}

Published online: 5 July 2019

(C) De La Salle University 2019

\section{Emotions In Learning And Teaching}

Students and teachers alike experience different types of emotions ranging from the positive (e.g., enjoyment) to the negative (e.g., anxiety). Despite the ubiquity of emotions, they have been relatively neglected in educational research. As Linnenbrink-Garcia and Pekrun (2011, p. 3) noted, "research on ... emotions is still in its early infancy".

The neglect of emotions is alarming given that "emotion is the foundation of learning" (Zull 2006, p. 7). Emotions stimulate learners' attention and trigger the learning process. They affect what is learned and what is retained. Numerous studies across a range of disciplines including neuroscience, education, and psychology have revealed that emotions play an important role in learning (Seli et al. 2016; Tyng et al. 2017; Um et al. 2012).

Aside from the role of emotions in learning, it is also a fundamental component of effective teaching (Hosotani and Imai-Matsumura 2011). Research has shown that teacher emotions play a crucial role in the learning and teaching process (e.g., Scott and Sutton 2009; Uitto et al. 2015; Yin et al. 2017). It has been argued that teacher emotion is a fundamental component of quality teaching (Day and Qing 2009; Hosotani and Imai-Matsumura 2011).

Ronnel B. King

ronnel@eduhk.hk

1 Department of Curriculum and Instruction, The Education University of Hong Kong, New Territories, Hong Kong

2 Department of Education Policy and Leadership, The Education University of Hong Kong, New Territories, Hong Kong
How teachers experience and express emotions have a direct impact on their teaching approach, which affect not only learners' behavior, but also how emotions are infused in classrooms (Chen 2017, 2018, 2019; Srinivasan 2015).

More recently, there has been an increasing recognition of the key role of emotions in educational settings. This special issue contributes to this growing body of work by providing a platform for showcasing the latest research on emotions in learning and teaching among Asian populations (see also Chen 2016, 2017, 2019; Ganotice et al. 2016; King and Areepattamannil 2014; King and Datu 2018; King et al. 2012; Yang 2016, 2018).

\section{Emotions in Asian Contexts}

While emotions are universal, how they are experienced, expressed, perceived, and regulated are influenced by culture and the surrounding society (Richeson and Boyd 2005). In collectivist contexts such as those found in China, Singapore, and the Philippines, strong emphasis is placed on attending to others, fitting in and maintaining harmonious interdependence. Individuals, therefore, are expected to control their own emotions and to be sensitive to the self and others' emotions so as to promote harmony (Oyserman et al. 2002). In contrast, in individualistic cultures in the West, the emphasis is on attending to the self and maintaining personal independence from others. Hence, individuals are encouraged to discover and express their emotions as well as other unique attributes (Markus and Kitayama 1991). Given that research on emotions is still dominated by Western societies, the distinctive emotional differences between the East and the West point to the need for more research in this area. 
The special issue aims to uncover the role of emotions in educational contexts with a special focus on the domains of learning and teaching. The focus on Asian research will help illuminate how the unique Asian sociocultural context influences the dynamic interplay among emotions, learning, and teaching. The special issue is organized into two sections.

The first section focuses on student emotions and their role in the learning process. It includes three papers which sampled students from P.R. China, Hong Kong, and Singapore. The section starts with the paper of Luo et al. (2019) who drew on a nationally representative sample of Chinese college students $(n=67,182)$ to examine emotional engagement, defined as students' affective reactions in school (Fredricks et al. 2004). Contrary to cultural stereotypes that Chinese learners are academically successful yet unhappy, they found that the majority of students were emotionally engaged in learning. Emotional engagement positively predicted satisfaction with the university experience and also strengthened the effect of cognitive engagement on students' overall satisfaction with their university life.

The second paper by Fong and Cai (2019) focused on test-related emotions, in particular hope. They surveyed Hong Kong primary school students $(n=1051)$ and modeled the relationships among perfectionism (including perfectionist striving and perfectionist concerns), selfcompassion, and test-related hope. They found that students who have high levels of perfectionist striving also had higher levels of test-related hope, and this relationship was partially mediated by self-compassion.

The third paper by Caleon et al. (2019) aimed to examine how the emotion of gratitude was associated with key educational outcomes among secondary school students from Singapore $(n=190)$. They found that students who experienced higher levels of gratitude were more resilient and had better school well-being. These associations were partially mediated by a higher sense of relatedness to significant others. Grateful students felt they had closer connections with their parents, teachers, and friends. These warm social relationships, in turn, partly explained their higher resilience and well-being.

The second section of the special issue is about the role of emotions in teaching and includes four papers. The section begins with the paper of Nalipay et al. (2019) who surveyed Filipino preservice teachers $(n=413)$ about teacher enjoyment. They demonstrated that preservice teachers who believed that their teaching ability could be developed (growth mindset towards teaching) were more likely to enjoy teaching. Enjoyment, in turn, positively predicted teaching satisfaction.

The next paper by Chen (2019) surveyed a sample of Chinese preservice teachers $(n=963)$ exploring the relationship between preservice teachers' efficacy, emotions, and practicum performance scores. Results showed that preservice teachers' efficacy significantly predicted their practicum performance through their emotions.

The sixth paper by Zhang et al. (2019) focused on the mediating role of teachers' coping styles in the relationship between psychological capital and burnout with a sample of 386 teachers from primary and secondary schools in China. Results of their study revealed that psychological capital protects teachers from burnout while occupational stress predisposes teachers to experiencing burnout.

The last paper by Lu (2019) tested a reciprocal model which examined teachers' sleep quality, passion, work engagement, and enjoyment. A sample of 137 teacher leaders in Hong Kong and 79 teacher leaders in Shanghai were recruited. Results of the cross-lagged path analysis indicated that that nurturing teacher passion is partly a within-person process. Teachers' passion can stem from their own work enjoyment and positive interactions with others in schools, for both of which good quality sleep is helpful.

Finally, the special issue concludes with a commentary from Hall who critiqued the papers in the special issue and proposed recommendations for moving emotions research forward. The empirical papers in this issue covered a wide range of Asian societies such as P.R. China, Hong Kong, Singapore, and the Philippines which have mostly been absent from the Western-dominated literature. Collectively, the papers in this special issue shed light on how crucial emotions are to learning and teaching, and we hope that this effort will spark greater regional and international interest in exploring the important role of emotions in the Asian educational context.

\section{References}

Caleon, I. S., Ilham, N. Q. B., Ong, C. L., \& Tan, J. P.-L. (2019). Cascading effects of gratitude: A sequential mediation analysis of gratitude, interpersonal relationships, school resilience and school well-being. The Asia-Pacific Education Researcher. https://doi.org/10.1007/s40299-019-00440-w.

Chen, J. (2016). Understanding teacher emotions: The development of a teacher emotion inventory. Teaching and Teacher Education, 55, 68-77.

Chen, J. (2017). Exploring primary teacher emotions in Hong Kong and Mainland China: A qualitative perspective. Educational Practice and Theory,39(2), 17-37.

Chen, J. (2019). Highly efficacious, positive teachers achieve more: Examining the relationship between teacher efficacy, emotions, and their practicum performance. The Asia-Pacific Education Researcher. https://doi.org/10.1007/s40299-018-0427-9.

Chen, J. (2019). Exploring the impact of teacher emotions on their approaches to teaching: A Structural Equation Modeling approach. British Journal of Educational Psychology,89, 57-74. https://doi.org/10.1111/bjep.12220. 
Day, C., \& Qing, G. (2009). Teacher emotions: Well-being and effectiveness. In P. A. Schutz \& M. Zembylas (Eds.), Advances in teacher emotion research: The impact on teachers' lives (pp. 15-32). London: Springer.

Fong, R. W., \& Cai, Y. Y. (2019). Perfectionism, self-compassion and test-related hope in Chinese primary school students. The AsiaPacific Education Researcher.

Fredricks, J. A., Blumenfeld, P. C., \& Paris, A. H. (2004). School engagement: Potential of the concept, state of the evidence. Review of Educational Research,74, 59-109.

Ganotice, F. A., Datu, J. A. D., \& King, R. B. (2016). Which emotional profiles exhibit the best learning outcomes? A person centered analysis of students' academic emotions. School Psychology International,37, 498-518.

Hosotani, R., \& Imai-Matsumura, K. (2011). Emotional experience, expression, and regulation of high-quality Japanese elementary school teachers. Teaching and Teacher Education,27, 1039-1048.

King, R. B., \& Areepattamannil, S. (2014). What students feel in school influences the strategies they use for learning: Academic emotions and cognitive/meta-cognitive strategies. Journal of Pacific Rim Psychology,8, 18-27.

King, R. B., \& Datu, J. A. D. (2018). Grateful students are motivated, engaged, and successful: Cross-sectional, longitudinal, and experimental evidence. Journal of School Psychology,70, $105-122$.

King, R. B., McInerney, D. M., \& Watkins, D. A. (2012). How you think about your intelligence determines how you feel in school: The role of theories of intelligence on academic emotions. Learning and Individual Differences, 22, 814-819.

Linnenbrink-Garcia, L., \& Pekrun, R. (2011). Students' emotions and academic engagement: Introduction to the special issue. Contemporary Educational Psychology,36, 1-3.

Lu, J. (2019). Reciprocal gain spirals: The relationships among sleep quality, work enjoyment, cooperative interaction, and work passion of teacher leaders. The Asia-Pacific Education Researcher. https://doi.org/10.1007/s40299-018-00430-4.

Luo, Y., Xie, M., \& Lian, Z. (2019). Emotional engagement and student satisfaction: A study of Chinese college students based on a nationally representative sample. The Asia-Pacific Education Researcher. https://doi.org/10.1007/s40299-019-00437-5.

Markus, H. R., \& Kitayama, S. (1991). Culture and the self: Implications for cognition, emotion and motivation. Psychological Review, 98, 224-253.

Nalipay, J. N., Mordeno, I. G., Semilla, J. B., \& Frondozo, C. E. (2019). Implicit beliefs about teaching ability, teacher emotions, and teaching satisfaction. The Asia-Pacific Education Researcher.

Oyserman, D., Coon, H. M., \& Kemmelmeier, M. (2002). Rethinking individualism and collectivism: Evaluation of theoretical assumptions and meta-analyses. Psychological Bulletin,128, 3-72.

Richeson, P. J., \& Boyd, R. (2005). Not by genes alone: How culture transformed human evolution. Chicago: University of Chicago Press.

Scott, C., \& Sutton, R. E. (2009). Emotions and change during professional development for teachers: A mixed methods study. Journal of Mixed Methods Research,3, 151-171.

Seli, P., Wammes, J. D., Risko, E. F., \& Smilek, D. (2016). On the relation between motivation and retention in educational contexts: The role of intentional and unintentional mind wandering. Psychonomic Bulletin \& Review,23, 1280-1287. https://doi.org/10.3758/s13423-015-0979-0.

Srinivasan, P. (2015). Exploring the influences of teacher's intelligence and emotional intelligence on students' academic achievement. American Journal of Educational Research,3(9), $1159-1162$.

Tyng, C. M., Amin, H. U., Saad, M. N. M., \& Malik, A. S. (2017). The influences of emotion on learning and memory. Frontiers in Psychology,8, 1454. https://doi.org/10.3389/fpsyg.2017.01454.

Uitto, M., Jokikokko, K., \& Estola, E. (2015). Virtual special issue on teachers and emotions in teaching and teacher education (TATE) in 1985-2014. Teaching and Teacher Education,50, 124-135.

Um, E., Plass, J. L., Hayward, E. O., \& Homer, B. D. (2012). Emotional design in multimedia learning. Journal of Educational Psychology,104, 485-498. https://doi.org/ 10.1037/a0026609.

Yang, L. (2016, August). Achievement Emotions of Chinese Students: An Investigation in Technical and Vocational Education. Paper presented at the 23rd International Congress of the International Association for Cross-Cultural Psychology, Nagoya, Japan.

Yang, L. (2018, June). Developing a 24 items' short-form of learningrelated achievement emotions questionnaire (SF-L-AEQ) in Chinese students. Poster presented at the 9th European Conference on Positive Psychology (ECPP), Budapest, Hungary.

Yin, H. B., Huang, S., \& Wang, W. (2017). Work environment characteristics and teacher well-being: The mediation of emotion regulation strategies. International Journal of Environment Research Public Health,13(9), 907.

Zhang, Y., Zhang, S., \& Hua, W. (2019). The impact of psychological capital and occupational stress on teacher burnout: Mediating role of coping styles. The Asia-Pacific Education Researcher. https://doi.org/10.1007/s40299-019-00446-4.

Zull, J. E. (2006). Key aspects of how the brain learns. In S. Johnson \& K. Taylor (Eds.), The neuroscience of adult learning (pp. 3-9). San Francisco: Jossey-Bass.

Publisher's Note Springer Nature remains neutral with regard to jurisdictional claims in published maps and institutional affiliations. 